\title{
Loss of specialists hurts research
}

It is no secret that the job market in medicine, once predictable and secure, has fallen apart during the past two years. In California, well-trained cardiologists cannot find work. In Florida, gastroenterologists are in oversupply, despite the fact that the state's large elderly population might be expected to be a rich source of patients with stomach troubles. The specialists are being replaced with what the United States
At the University of California at San Francisco, Donald Ganem, whose laboratory is well supported by the Howard Hughes Medical Institute (HHMI), tells an anecdote that is all too revealing of the anxiety among postdoctoral fellows. On the basis of epidemiological evidence that Kaposi's sarcoma might be caused by a virus, he set out to find it.

The search was a long shot that Ganem, an established HHMI physicianscientist, was willing to take. The postdoctoral fellows in his laboratory then were not as willing to take the risk. He could never get more than one fellow to look for the KS

calls primary-care or family doctors, who are now much sought after by hospitals and clinics run by managed care organizations that are determined to reduce costs by employing more medical generalists and by paying them less than their colleagues in specialty medicine.

Indeed, primary care is all the rage as medicine, like fashion, follows the latest fads. One indication that the marketplace is driving the future lies in the choices of "specialty" by this year's crop of medical school graduates. No residency positions in primary care are unfilled, but for the first time there are residency training slots in anesthesiology and pathology that are going begging.

Young physicians and biomedical PhDs who have this year finally completed years of grueling training are also facing a new reality. Even the best and the brightest MDs are finding it next to impossible to find good jobs in academic medicine where they can combine clinical practice with basic research. In a recent article in the Johns Hopkins Medical News, some of Hopkins best young physicians and scientists spoke openly about difficult job hunting. One MD-PhD who has accepted a faculty position at Hopkins that does combine medicine and research reported interviews with several department chairs who all had the same message: "Two or three years ago, I would have offered you a job right now, but I can't possibly do that any more because of the economic realities of my department." Another MD-PhD, whose mentor is a Nobel laureate, also landed a plum faculty position but only after a search of 15 months. But many would-be physician-scientists will have to compromise, taking clinical positions without being able to pursue research. virus at a time, he reports. "Even though I had made the decision to work on this and HHMI had supported my decision," the risk of failure was too great. Now that the virus has been found (at Columbia University as it turned out), "I have no trouble getting people to work in KS," says Ganem. But, he notes, searching for an"entirely new pathogen was always considered high-risk science in academia. "It can be a career-breaking event to fail."

Does any of this really matter? Strong arguments exist for adjusting the supply of highly trained MDs and PhDs to the reality of tighter clinical and research markets. Indeed, Ganem is reducing the number of people he will take into his own graduate program. Hopkins is beginning to reduce selectively the number of its residency and fellowship slots. Duke University Hospital, which has 495 residents, is cutting residency positions by $30 \%$ during the next four years. In Boston, the Massachusetts General Hospital and Brigham and Women's Hospital will reduce residency training by $20 \%$. It is a sign of the times. It is interesting that the leaders in the "downsizing" movement are the very institutions that are among the best intellectually. The loss of residency positions will inevitably reduce the number of graduates of foreign medical schools who can receive advanced training in the United States, as well as the those who use that springboard to pursue careers here.

Retrenchment is not all bad, but it is certain that, in the short run, research and clinical research will be damaged. It is far less certain that the care of patients will improve proportionately. But in the absence of a sensible national health-care plan, the marketplace is going to go on wreaking change until the government or patients or doctors (page 735) say "enough."

- Barbara J. Culliton 